\title{
Germplasm Evaluation of Glycine max for Resistance to Fusarium solani, the Causal Organism of Sudden Death Syndrome
}

\author{
G. L. Hartman, USDA, Agricultural Research Service, and Department of Crop Sciences, 70 EASB, 1101 W. Pea- \\ body; Y. H. Huang, Department of Crop Sciences; and R. L. Nelson and G. R. Noel, USDA, Agricultural Research \\ Service, and Department of Crop Sciences, University of Illinois at Urbana-Champaign, Urbana 61801-4723
}

\begin{abstract}
Hartman, G. L., Huang, Y. H., Nelson, R. L., and Noel, G. R. 1997. Germplasm evaluation of Glycine max for resistance to Fusarium solani, the causal organism of sudden death syndrome. Plant Dis. 81:515-518.

Sudden death syndrome (SDS) is an important soybean disease that potentially can be controlled by host plant resistance. In this study, over 800 soybean plant introductions (PIs), lines, and cultivars were screened for resistance to Fusarium solani. Of 728 PIs from China, PI 567.374 had mean foliar SDS severities significantly $(P=0.05)$ lower than PI 520.733 (resistant check) in both growth-chamber and greenhouse tests. In addition, PIs 567.315, 567.441C, 567.650B, and 567.664 had mean SDS severity ratings significantly $(P=0.05)$ lower than PI 520.733 in a growth-chamber test. Of 16 soybean cyst nematode-resistant entries tested, 5 had values lower than the resistant check, PI 520.733, with cv. Hartwig significantly lower in the first trial. In trial two, no entries were lower than the resistant check, although cvs. Bell and Hartwig were not significantly different from PI 520.733. In another experiment, few soybean cultivars or experimental lines had SDS severity ratings lower than PI 520.733 in any one of three trials. Some of the newly acquired PIs from China that exhibited low foliar SDS severity ratings may provide the sources of resistance needed to develop new SDS-resistant soybean breeding lines and cultivars.
\end{abstract}

Additional keywords: soybean disease resistance, toxin resistance

Sudden death syndrome (SDS) of soybean is caused by Fusarium solani (Mart.) Appel \& Wollenw. emend. Synd. \& Hans. $(14,15)$ and has been reported in major soybean-production areas in the United States $(5,7,20)$. Although estimated yield reductions are relatively low compared to other soybean diseases in the South (20), in certain situations it can be severe. For example, in east-central Illinois in 1993, SDS was reported in $46 \%$ of the soybean fields surveyed, with estimated yield losses ranging from 20 to $46 \%$ (5).

The pathogen is isolated from roots, and occasionally from lower stems $(14,15)$. The most striking symptoms of the disease occur on leaves, as interveinal chlorosis and necrosis. Leaves often drop from the plant, leaving the petiole attached to the stem. The

Corresponding author: G. L. Hartman E-mail: ghartman@uiuc.edu

Mention of a trademark or proprietary product does not constitute a guarantee or warranty of the product by the U.S. Department of Agriculture and does not imply its approval to the exclusion of other products that may also be suitable.

Accepted for publication 6 February 1997.

Publication no. D-1997-0310-04R

This article is in the public domain and not copyrightable. It may be freely reprinted with customary crediting of the source. The American Phytopathological Society, 1997. foliar phase of the disease is easy to see, because plants in infected areas of the field prematurely turn yellow to brown, whereas plants not exhibiting foliar symptoms remain green.

Resistance to $F$. solani, based on severity of foliar symptoms, has been reported in both field and greenhouse experiments. Several techniques have been used to evaluate soybean for SDS resistance under greenhouse conditions $(4,13,18)$, but a limited number of soybean genotypes have been screened $(7,13,16)$. Qualitative resistance has been reported in cv. Ripley (18), and quantitative resistance has been reported in cv. Forrest (8) and in variants of regenerated plants of cv. Jack obtained from in vitro selection of embryogenic cultures (10). An additional source with resistance to both SDS and soybean cyst nematode (SCN), Heterodera glycines, recently was released (6).

The USDA Soybean Germplasm Collection contains more than 16,000 accessions but has not been systematically screened for resistance to $F$. solani. Our objective was to find resistance to $F$. solani based on severity of SDS foliar symptoms in newly acquired germplasm from China, SCN-resistant lines, and a set of mostly modern cultivars.

\section{MATERIALS AND METHODS}

Inoculum increase, inoculations, and SDS symptom severity ratings. An isolate of $F$. solani, Monticello (originating from Monticello, IL), was maintained in the dark at $23^{\circ} \mathrm{C}$ on solidified agar medium consisting of $1 \mathrm{~g}$ of $\mathrm{KH}_{2} \mathrm{PO}_{4}, 1 \mathrm{~g}$ of $\mathrm{KNO}_{3}$, $0.5 \mathrm{~g}$ of $\mathrm{MgSO}_{4} \cdot \mathrm{H}_{2} \mathrm{O}, 0.5 \mathrm{~g}$ of $\mathrm{KCl}, 0.2 \mathrm{~g}$ of potato starch, $0.2 \mathrm{~g}$ of sucrose, and $8 \mathrm{~g}$ of agar per liter. The fungus was increased on $200 \mathrm{~g}$ of red-sorghum seeds that were soaked overnight and autoclaved twice in a 1-liter flask. Each flask was inoculated with 10 plugs ( $4 \mathrm{~mm}$ diameter) of fungal mycelium and incubated for 2 weeks. Two liters of a greenhouse steam-treated soil mix (1:1 $\mathrm{sand} /$ soil) was placed in $8 \times 12-\mathrm{cm}$ galvanized trays. A template was used to make three furrows that were $12 \mathrm{~cm}$ long, $2 \mathrm{~cm}$ deep, and $3 \mathrm{~cm}$ apart, and $5 \mathrm{~cm}^{3}$ of infested sorghum seeds was evenly distributed in each furrow. About $800 \mathrm{~cm}^{3}$ of soil mix was added to cover the infested seeds to a depth of $2 \mathrm{~cm}$. The template was reapplied to make a 2-cm-deep furrow directly over the inoculum. Twelve seeds per entry were added to each furrow, which was covered with another $800 \mathrm{~cm}^{3}$ of soil mix $(2 \mathrm{~cm}$ deep), per tray.

After seedling emergence, the soil was maintained at near water-holding capacity by flooding the flats twice daily as needed. Three weeks after planting, unless otherwise stated, each plant was evaluated for SDS leaf symptoms: 1 = no symptoms, 2 = slight symptom development, with mottling and mosaic on leaves (1 to $20 \%$ foliage affected), 3 = moderate symptom development, with interveinal chlorosis and necrosis on foliage ( 21 to $50 \%$ foliage affected), $4=$ heavy symptom development, with interveinal chlorosis and necrosis (51 to $80 \%$ ), and $5=$ severe interveinal chlorosis and necrosis (81 to $100 \%$ foliage affected).

Chinese germplasm. Recently acquired soybean germplasm, representing 728 plant introductions (PIs 567.290 to 567.781) from nine central Chinese provinces, was inoculated with $F$. solani in a series of trials under greenhouse conditions. In the first stage, all genotypes plus three standards (PI 520.733 and cvs. Ripley and Great Lakes 3202) were evaluated. The three standards were chosen to represent a range of foliar disease severities based on previous studies $(5,11,18)$. The entries were arranged in eight sets. Entries within sets that had a mean disease severity of 1 standard deviation (SD) below the mean of the set were advanced. In the second stage, 133 PIs from stage one and the standards plus cvs. Jack (intermediate) and Spencer (susceptible) were 
inoculated in two sets. Entries with mean disease severity ratings less than $1 \mathrm{SD}$ from the mean disease severity of the set were tested in a randomized complete block (RCB) design with two replications. The experiment was repeated in a growth chamber at $25^{\circ} \mathrm{C}$ and 12 hours of light $\left(300 \mu \mathrm{E} \mathrm{m}^{-2} \mathrm{~s}^{-1}\right)$ per day.

SCN resistance. Eighteen SCN-resistant entries, representing popular cultivars and PIs and four checks (PI 520.733 and cvs. Ripley, Spencer, and Williams 82 [all susceptible to SCN]), were inoculated with $F$. solani in two experiments in separate greenhouses in a RCB design with two replications each.

Selected lines and cultivars. Thirty soybean entries (distributed by P. Gibson for SDS evaluations at multiple sites), representing a set ranging from susceptible to resistant to $F$. solani, were inoculated in flats, as described previously, in a greenhouse and growth chamber $\left(25^{\circ} \mathrm{C}\right)$, in a RCB design with two replications, and under field conditions, in microplots with three replications. For the microplot inoculation, PVC pipe (10 cm diameter) was filled with 1.5 liters of greenhouse soil. Ten cubic centimeters of inoculum was placed in the cylinder. Soil was added to cover the infested seeds to a depth of $2 \mathrm{~cm}$, and soybean seeds were planted and covered with soil to a depth of $2 \mathrm{~cm}$. Five seeds were used in each container and thinned to three plants. The experiment was designed as a $\mathrm{RCB}$ with three replications, with three plants per replication. Disease severity was rated $14,16,19$, and 21 days after sowing in the greenhouse, one rating was done at 21 days in the growth chamber, and ratings were done at $22,26,30$, and 34 days after sowing in the field.

Data analysis. In all replicated experiments, disease severity ratings were converted to percent midpoint values (3), where an SDS severity rating of $1=0 \%, 2=10 \%, 3=$ $35 \%, 4=65 \%$, and $5=90 \%$, before running analysis of variance (SAS Institute, Cary, NC). Means were separated by least significant difference at $P=0.05$. To evaluate selected lines and cultivars that had multiple disease severity ratings, area under disease progress (AUDPC) values were calculated (17) based on midpoint values.

\section{RESULTS}

Chinese germplasm. Among the eight sets initially screened, the mean disease se-

Table 1. Mean sudden death syndrome severity ratings of 22 recently acquired soybean plant introductions and 5 standard soybean entries in replicated growth-chamber and greenhouse experiments 3 weeks after inoculation with Fusarium solani

\begin{tabular}{|c|c|c|c|c|c|}
\hline \multirow[b]{2}{*}{$\begin{array}{l}\text { Soybean } \\
\text { entry }\end{array}$} & \multirow[b]{2}{*}{$\begin{array}{l}\text { Chinese } \\
\text { province }\end{array}$} & \multirow[b]{2}{*}{$\begin{array}{c}\text { Maturity } \\
\text { group }\end{array}$} & \multicolumn{3}{|c|}{ Severity ratings $(\%)^{\mathrm{a}}$} \\
\hline & & & 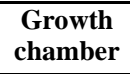 & Greenhouse & Mean \\
\hline PI 567.374 & Shaanxi & IV & 18 & 21 & 20 \\
\hline PI 567.315 & Gansu & $\mathrm{V}$ & 26 & 34 & 30 \\
\hline PI 567.650B & Henan & IV & 27 & 33 & 30 \\
\hline PI 567.664 & Henan & IV & 34 & 34 & 34 \\
\hline PI $567.441 \mathrm{C}$ & Shaanxi & $\mathrm{V}$ & 29 & 40 & 36 \\
\hline PI 567.765D & Jiangsu & IV & 50 & 22 & 36 \\
\hline PI 567.356 & Gansu & V & 45 & 31 & 38 \\
\hline PI 567.627C & Henan & IV & 40 & 35 & 38 \\
\hline PI 567.323B & Gansu & II & 43 & 37 & 40 \\
\hline PI 567.701 & Anhui & IV & 42 & 48 & 44 \\
\hline PI 567.649 & Henan & III & 48 & 43 & 46 \\
\hline PI 567.429B & Shaanxi & III & 50 & 44 & 47 \\
\hline PI 567.464 & Shaanxi & IV & 47 & 53 & 50 \\
\hline PI 567.610B & Henan & IV & 55 & 46 & 51 \\
\hline PI 567.321A & Gansu & IV & 51 & 52 & 52 \\
\hline PI 567.379A & Shaanxi & $\mathrm{V}$ & 55 & 48 & 52 \\
\hline PI 567.588B & Shandong & IV & 54 & 50 & 52 \\
\hline PI 567.351B & Gansu & III & 52 & 53 & 53 \\
\hline PI 567.635 & Henan & $\mathrm{V}$ & 51 & 54 & 53 \\
\hline PI 567.326B & Gansu & V & 58 & 56 & 57 \\
\hline PI 567.325A & Gansu & II & 52 & 63 & 58 \\
\hline PI520.733 & & V & 40 & 47 & 44 \\
\hline Jack & & III & 48 & 42 & 45 \\
\hline Ripley & & III & 58 & 52 & 55 \\
\hline Great Lakes 3202 & & III & 56 & 56 & 56 \\
\hline Spencer & & IV & 65 & 63 & 64 \\
\hline Mean & & & 46 & 45 & \\
\hline $\operatorname{LSD}(P=0.05)$ & & & 17 & 16 & \\
\hline Coefficient of variation (\%) & & & 18 & 17 & \\
\hline
\end{tabular}

${ }^{a}$ Symptoms based on foliar severity ratings of individual plants (usually 10 plants per entry): $1=$ no symptoms, 2 = slight symptom development, with mottling and mosaic on leaves ( 1 to $20 \%$ foliage affected), 3 = moderate symptom development, with interveinal chlorosis and necrosis on foliage ( 21 to $50 \%$ foliage affected), $4=$ heavy symptom development, with interveinal chlorosis and necrosis $(51$ to $80 \%$ ), and $5=$ severe interveinal chlorosis and necrosis ( 81 to $100 \%$ foliage affected). Data were converted to midpoint values (3) based on the range within each severity rating scale.

verity rating was 3.4 , compared to ratings of 2.5 for PI 520.733, 3.7 for cv. Ripley, and 4.0 for cv. Great Lakes 3202. In the second stage, the mean severity rating of the remaining 133 PIs was 2.8 , compared to mean SDS severities of 2.5 for PI520.733, 3.1 for Ripley, and 3.2 for Great Lakes 3202. In stage three (replicated experiments), the data from the growth chamber and greenhouse were analyzed separately, because the combined data had a significant $(P=0.05)$ interaction between the trial location and entries. The mean SDS severities for the growth chamber and greenhouse experiments were 46 and $45 \%$, respectively (Table 1). PI 567.374 had mean disease severity ratings significantly $(P=$ $0.05)$ lower than PI 520.733 in both the growth-chamber and greenhouse tests. In at least one of the trials, PIs 567.315, 567.441C, 567.650B, and 567.664 had mean disease severity ratings significantly $(P=0.05)$ lower than PI 520.733.

SCN resistance. The combined data of the two trials showed a significant trial by entry interaction, so the data analysis for each trial is presented (Table 2). The mean disease severity for trials one and two was 71 and $67 \%$, respectively. In the first trial, five entries had values lower than the resistant check, PI 520.733, with cv. Hartwig significantly lower. In trial two, no entries were lower than the resistant check, although cvs. Bell and Hartwig were not significantly different from PI 520.733.

Selected lines and cultivars. The mean AUDPC value in the greenhouse was 345; cv. Jack had the lowest AUDPC. In the growth chamber, PI 520.733 had the lowest 3 -week rating. Of the 10 entries with the lowest AUDPC in the greenhouse test, 7 had the lowest disease severity ratings in the growth-chamber experiment. The seven entries with the lowest disease severity ratings in the growth chamber were PI 520.733 (22\%) and cvs. Ripley (31\%), Forrest (34\%), Hartz 6686 (35\%), BSR 101 (37\%), Bass $(38 \%)$, and Jack $(42 \%)$. There was a significant $(P<0.05)$ correlation $(r=0.42)$ between AUDPC values in the greenhouse and the 21-day rating in the growth chamber. The coefficient of variation was 20 , 25 , and $67 \%$ for the greenhouse AUDPC values, growth-chamber 21-day rating, and microplot AUDPC values, respectively. The microplot data had a high level of variation, and the data could not be normalized for ANOVA, although there was a significant $(P=0.05)$ correlation $(r=0.43)$ between data for AUDPC values collected from the greenhouse and AUDPC values from the microplots.

\section{DISCUSSION}

Evaluations of SDS resistance have been conducted with limited numbers of entries or mostly cultivated soybeans $(13,16)$. Some soybean genotypes have been identified as having some resistance to SDS, although no entries have complete resistance and se- 
lection for improved resistance has been slow due to limited understanding of the inheritance of SDS resistance. Based on our results, most of the soybean germplasm we tested was susceptible. Although our results are from greenhouse screenings, there is evidence in our data and the data of others (19) that indicates a relationship in foliar symptom severity between field and greenhouse results.

Although there is some variation in our greenhouse data, we found that the coefficient of variation was usually lower than $25 \%$, which was more reliable than our field data. Others rarely report the same degree of variation between replications, repeated experiments, or field locations when evaluating soybeans for $F$. solani resistance. The sporadic occurrence of SDS in terms of its spatial and temporal patterns makes it difficult to accurately evaluate resistance in the field.

Although races of $F$. solani were reported in an abstract (11), there apparently are no additional reports indicating there are races of $F$. solani. One of the PIs used to determine races was PI 520.733, which originates from Korea. This PI has large seeds (23 g per 100 seeds), and normally, seedlings are more vigorous than for other genotypes. It also had one the lowest SDS severities in field trials in 1995 (P. Gibson, personal communication). The $F$. solani isolate used in this study was the isolate selected by a working group of SDS researchers for comparison of soybean entries by several participants at different locations (L. Achenbach, personal communication). This particular isolate was one of the most virulent isolates in a previous report (4) and in our own studies.

The soybean germplasm we tested represented 728 soybean accessions that originated from nine central provinces in China. Of 94 entries screened from Gansu Province, 8 were in the 22 entries selected in the final screening. Most provinces had just a few entries in the final list of 22, and one province, Hebei, had no entries in the final 22. Even though most accessions screened came from Shandong Province (149) and the least from Ningxia Province (25), these two provinces contributed 2 and 1 lines, respectively, to the 22 most resistant lines. There are no reports of SDS from China, so it is not known why there was a differential response of Chinese germplasm to $F$. solani, because there presumably was not any selection pressure on soybeans to develop resistance. Discerning geographic patterns of genetic diversity in soybean is still difficult because of the limited number of accessions available from most provinces in China; the establishment of such relationships would be an important germplasm management tool. There was no other relationship between the level of resistance and any other agronomic characteristic, including maturity group, which ranged from II to V.

Table 2. Mean sudden death syndrome severity ratings of soybean cyst nematode (SCN)-resistant soybean entries and three standard entries in two replicated experiments conducted in different greenhouses 3 weeks after inoculation with Fusarium solani

\begin{tabular}{llccc}
\hline & \multirow{2}{*}{$\begin{array}{c}\text { Source of } \\
\text { SCN resistance }\end{array}$} & Trial 1 & Trial 2 & Mean \\
\cline { 2 - 3 } Soybean entry & PI 437.654 & 51 & 53 & 52 \\
\hline Hartwig & PI 88.788 & 64 & 54 & 59 \\
Bell & Peking & 59 & 68 & 64 \\
CN290 & Cloud & 71 & 62 & 67 \\
LN89-5612 & PI 90.763 & 68 & 66 & 67 \\
PI 90.763 & PI 88.788 & 61 & 74 & 68 \\
Jack & Peking & 65 & 73 & 69 \\
Newton & PI 209.332 & 74 & 67 & 71 \\
LN89-5699 & Peking & 60 & 83 & 72 \\
Peking & PI 88.788 & 69 & 76 & 73 \\
PI 88.788 & PI 89.772 & 73 & 72 & 73 \\
PI 89.772 & PI 88.788 & 82 & 66 & 74 \\
Linford & PI 88.788 & 80 & 69 & 75 \\
Fayette & Cloud & 84 & 71 & 78 \\
Cloud & PI 89.772 & 87 & 75 & 81 \\
LN89-5717 & PI 437.654 & 79 & 86 & 83 \\
PI 437.654 & None known & 65 & 33 & 49 \\
PI 520.733 & None known & 74 & 68 & 71 \\
Ripley & None known & 87 & 66 & 77 \\
Spencer & None known & 86 & 80 & 83 \\
Williams82 & & 71 & 67 & \\
Mean & & 19 & 22 & \\
LSD $(P=0.05)$ & & 18 & 20 & \\
Coefficient of variation (\%) & & &
\end{tabular}

a Symptoms based on foliar severity ratings of individual plants (usually 10 plants per entry): $1=$ no symptoms, 2 = slight symptom development, with mottling and mosaic on leaves ( 1 to $20 \%$ foliage affected), 3 = moderate symptom development, with interveinal chlorosis and necrosis on foliage (21 to 50\% foliage affected), 4 = heavy symptom development, with interveinal chlorosis and necrosis $(51$ to $80 \%$ ), and $5=$ severe interveinal chlorosis and necrosis ( 81 to $100 \%$ foliage affected). Data were converted to midpoint values (3) based on the range within each severity rating scale.

There is a need for combined resistance to $F$. solani and $\mathrm{SCN}$, because there seems to be a synergistic interaction between the two organisms (12). In our screening of SCN-resistant material, only cvs. Bell and Hartwig had disease ratings similar to PI 520.733. The pedigree of cv. Hartwig is cv. Forrest $^{3} \times$ PI 437.654 (1). Because Forrest has some resistance to SDS (8), it is not surprising that Hartwig also carries that resistance. There are no known sources of resistance in the ancestry of Bell (2), and additional tests are needed to verify its level of resistance.

Most research dealing with soybean resistance to $F$. solani has been based on lack of foliar symptoms, not on decreased colonization of roots by $F$. solani. One report recently indicated that $F$. solani isolates caused crown and root rot of soybeans, and differences in foliar, but not root rot severity, were observed between cvs. Ripley (resistant) and Spencer (susceptible) (4). In our own studies, we also have observed that the entries with the most foliar resistance and susceptibility do not seem to have differences in root infection and colonization (G. L. Hartman and Y. H. Huang, unpublished data). More research needs to be conducted to determine whether there is a source of resistance to $F$. solani root infection in the soybean germplasm.

It appears that resistance in soybeans to the foliar disease phase of SDS has some relationship with a toxin produced by the fungus (9). The mechanism of this resistance is unknown, but it could be related to reduced toxin accumulation, reduced translocation, detoxification, or a combination of these and other factors. Additional studies are needed to monitor toxin production and movement in plants of both resistant and susceptible types to determine the mechanisms involved in this host-pathogen interaction.

\section{ACKNOWLEDGMENTS}

This research was supported in part by the North Central Soybean Research Program and the United Soybean Board. We thank R. Warsaw (USDA/ARS agricultural research technician) for technical assistance in the greenhouse assays.

\section{LITERATURE CITED}

1. Anand, S. C. 1992. Registration of 'Hartwig' soybean. Crop Sci. 32:1069-1070.

2. Bernard, R. L., Juvik, G. A., Hartwig, E. E., and Edwards, C. J., Jr. 1988. Origins and Pedigrees of Public Soybean Varieties in the United States and Canada. USDA Technical Bulletin 1746. National Technical Information Service, Springfield, VA.

3. Campbell, C. L., and Madden, L. V. 1990. Introduction to Plant Epidemiology. John Wiley \& Sons, New York.

4. Gray, L. E., and Achenbach, L. A. 1996. Severity of foliar symptoms and root and crown rot of soybean inoculated with various isolates and inoculum rates of Fusarium solani. Plant Dis. 80:1197-1199.

5. Hartman, G. L., Noel, G. R., and Gray, L. E. 1995. Occurrence of soybean sudden death syndrome in east-central Illinois and associated yield losses. Plant Dis. 79:314-318.

6. Hartwig, E. E., Young, L. D., and Gibson, P. 
1996. Registration of soybean germplasm line D83-3349 resistant to sudden death syndrome, soybean cyst nematode, and two root-knot nematodes. Crop Sci. 36:212.

7. Hershman, D. E., Hendrix, J. W., Stuckey, R. E., Bachi, P. R., and Henson, G. 1990. Influence of planting date and cultivar on soybean sudden death syndrome in Kentucky. Plant Dis. 74:761-766.

8. Hnetkovsky, N., Chang, S. J. C., Doubler, T. W., Gibson, P., and Lightfoot, D. 1996. Genetic mapping of loci underlying field resistance to soybean sudden death syndrome. Crop Sci. 36: 393-400.

9. Jin, H., Hartman, G. L., Nickell, C. D., and Widholm, J. M. 1996. Phytotoxicity of culture filtrates from Fusarium solani, the causal agent of sudden death syndrome of soybean. Plant Dis. 80:922-927.

10. Jin, H., Hartman, G. L., Nickell, C. D., and Widholm, J. M. 1996. Characterization and purification of a phytotoxin produced by $\mathrm{Fu}$ - sarium solani, the causal agent of soybean sudden death syndrome. Phytopathology 86:277-282.

11. Lim, S. M., and Jin, H. 1991. Pathogenic variability in Fusarium solani isolated from soybeans with sudden death syndrome symptoms. (Abstr.) Phytopathology 81:1236.

12. McLean, K. S., and Lawrence, G. W. 1993. Interrelationship of Heterodera glycines and Fusarium solani in sudden death syndrome of soybean. J. Nematol. 25:434-439.

13. Melgar, J., and Roy, K. W. 1994. Soybean sudden death syndrome: Cultivar reactions to inoculation in a controlled environment and host range and virulence of causal agent. Plant Dis. 78:265-268.

14. Roy, K. W., Lawrence, G. W., Hodges, H. H., Mclean, K. S., and Killebrew, J. F. 1989. Sudden death syndrome of soybean: Fusarium solani as incitant and relation of Heterodera glycines to disease severity. Phytopathology 79:191-197.

15. Rupe, J. C. 1989. Frequency and pathoge- nicity of Fusarium solani recovered from soybeans with sudden death syndrome. Plant Dis. 73:581-584.

16. Rupe, J. C., Gbur, E. E., and Marx, D. M 1991. Cultivar responses to sudden death syndrome of soybean. Plant Dis. 75:47-50.

17. Shaner, G., and Finney, R. E. 1977. The effect of nitrogen fertilization on the expression of slow mildewing resistance in Knox wheat. Phytopathology 67:1051-1056.

18. Stephens, P. A., Nickell, C. D., and Kolb, F. L. 1993. Genetic analysis of resistance to Fusar ium solani in soybean. Crop Sci. 33:929-930.

19. Stephens, P. A., Nickell, C. D., Moots, C. K., and Lim, S. M. 1993. Relationship between field and greenhouse reactions of soybean to Fusarium solani. Plant Dis. 77:163-166.

20. Wrather, J. A., Chambers, A. Y., Fox, J. A., Moore, W. F., and Sciumbato, G. L. 1995 Soybean disease loss estimates for the south ern United States, 1974 to 1994. Plant Dis. 79: 1076-1079. 